\title{
Study on Unbalanced Weight Problem's Existence of 25m Rail Based on Simulation Analysis
}

\author{
Hang Zheng \\ School of Traffic and Transportation \\ Beijing Jiaotong University \\ Beijing, China \\ zhenghang7@163.com \\ Mei Han \\ School of Traffic and Transportation \\ Beijing Jiaotong University \\ Beijing, China \\ mhan@bjtu.edu.cn
}

\author{
Zhe Fang \\ School of Traffic and Transportation \\ Beijing Jiaotong University \\ Beijing, China \\ 13120834@bjtu.edu.cn
}

\begin{abstract}
Aiming at the unbalanced weight problem of $25 \mathrm{~m}$ rail in the railway transportation, this paper firstly uses the principle of moment balance and bending deformation principle to make theoretical analysis, and then establishes the finite element model of $25 \mathrm{~m}$ rail for simulation, and get the weight that the vehicle steering frames bear, and then judge the existence of unbalanced weight. The results show that current $25 \mathrm{~m}$ rail loading scheme in our country has led to unbalanced weight problem.
\end{abstract}

Keywords-railway transportation; 25m rail; unbalanced weight; deflection; simulation

\section{INTRODUCTION}

With the rapid development of Chinese railway enterprise, rail transportation demand every year is very huge, of which $25 \mathrm{~m}$ rail transportation occupies a large proportion. At present, Chinese $25 \mathrm{~m}$ rail transport mainly adopts six fulcrum cargo bogie straddle transport way, as shown in Figure 1, but this mode of transport in the actual operation usually leads to unbalanced weight problem ${ }^{[1]}$. Unbalanced weight means the weight of the goods shelf to withstand is more than half of the allowable load truck,or the difference in weight which two bogies withstand is greater than $10 \mathrm{t}^{[2]}$.When unbalanced weight problem takes place, it may lead to train crash accident and cause large lose. Therefore, it is very important to study on the unbalanced problem of $25 \mathrm{~m}$ rail.

The current study shows that, the bearing and the vehicles suspension state, the fulcrum and the car floor height, and line state can cause unbalanced weight to a certain extent, using four fulcrums to bear $25 \mathrm{~m}$ rail, using two supporting cargo bogie, and developing special $25 \mathrm{~m}$ rail transport vehicle can reduce unbalanced weight to a certain extent, but these ways can not fundamentally solve the problem ${ }^{[3]}$.

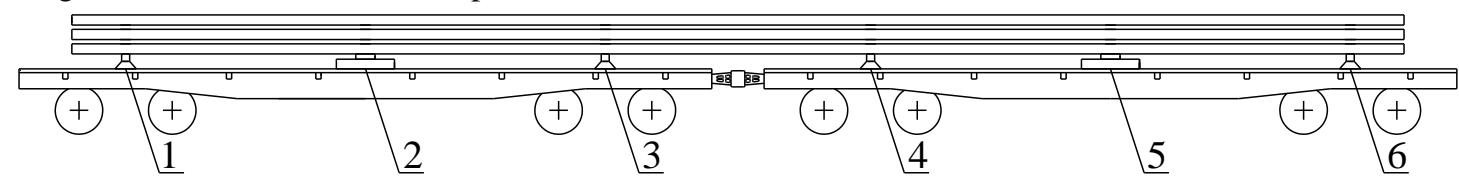

Figure 1. The $25 \mathrm{~m}$ rail transported by six fulcrum cargo bogie

This paper uses simulation to analysis, and get the weight that the vehicle steering frames bear, and then judge the existence of unbalanced weight.

\section{ANALYSIS OF RAIL MECHANICAL MODEL}

A. The calculation principle of weight fulcrums bear

When analysising the stress of rail, the rail is regarded as a simply supported beam, and due to its four redundant constraints, it is statically indeterminate beam whose statically indeterminate number is 4 . Assuming 2 5 pivot 
point constraint is redundant constraints, and envisaging the restrictions are lifted, it gets static basis for statically indeterminate beams, and then by using constraint force $F_{2} 、 F_{3} 、 F_{4} 、 F_{5}$ to instead redundant constraints respectively, it gets pretty system of statically indeterminate beams, as shown in figure $2^{[4]}$.

In order to ensure equivalent system and the original statically indeterminate beams have the same force deformation, the deflection must be 0 , which can establish the equation.

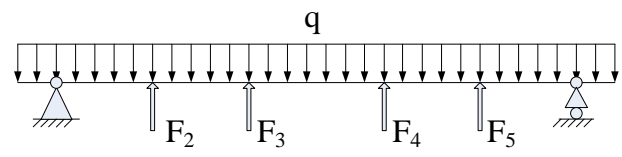

Figure 2. Example of a ONE-COLUMN figure caption

$$
\begin{aligned}
& \left(L^{2}-L_{26}^{2}-L_{12}^{2}\right) L_{26} F_{2}+\left(L^{2}-L_{36}^{2}-L_{12}^{2}\right) L_{36} F_{3}+\left(L^{2}-L_{46}^{2}-L_{12}^{2}\right) L_{46} F_{4}+\left(L^{2}-L_{56}^{2}-L_{12}^{2}\right) L_{56} F_{5} \\
& -0.25 q L\left(L^{3}-2 L L_{12}^{2}+L_{12}^{3}\right)=0 \\
& {\left[\left(L^{2}-L_{26}^{2}\right) L_{13}+L_{23}^{3} L / L_{26}-L_{13}^{3}\right] L_{26} F_{2}+\left(L^{2}-L_{36}^{2}-L_{13}^{2}\right) L_{36} L_{13} F_{3}+\left(L^{2}-L_{46}^{2}-L_{13}^{2}\right) L_{46} L_{13} F_{4}} \\
& +\left(L^{2}-L_{56}^{2}-L_{13}^{2}\right) L_{56} L_{13} F_{5}-0.25 q L L_{13}\left(L^{3}-2 L L_{13}^{2}+L_{13}^{3}\right)=0 \\
& {\left[\left(L^{2}-L_{26}^{2}\right) L_{14}+L_{24}^{3} L / L_{26}-L_{14}^{3}\right] L_{26} F_{2}+\left[\left(L^{2}-L_{36}^{2}\right) L_{14}+L_{34}^{3} L / L_{36}-L_{14}^{3}\right] L_{36} F_{3}+\left(L^{2}-L_{46}^{2}-L_{14}^{2}\right)} \\
& L_{46} L_{14} F_{4}+\left(L^{2}-L_{56}^{2}-L_{14}^{2}\right) L_{56} L_{14} F_{5}-0.25 q L L_{14}\left(L^{3}-2 L L_{14}^{2}+L_{14}^{3}\right)=0 \\
& {\left[\left(L^{2}-L_{26}^{2}\right) L_{15}+L_{25}^{3} L / L_{26}-L_{15}^{3}\right] L_{26} F_{2}+\left[\left(L^{2}-L_{36}^{2}\right) L_{15}+L_{35}^{3} L / L_{36}-L_{15}^{3}\right] L_{36} F_{3}+\left[\left(L^{2}-L_{46}^{2}\right) L_{15}\right.} \\
& \left.+L_{45}^{3} L / L_{46}-L_{15}^{3}\right] L_{46} F_{4}+\left[\left(L^{2}-L_{56}^{2}\right) L_{15}-L_{15}^{3}\right] L_{56} F_{5}-0.25 q L L_{15}\left(L^{3}-2 L L_{15}^{2}+L_{15}^{3}\right)=0 \\
& L-\text { Distance between pivot } 1 \text { and } 6, \mathrm{~m} \text {; } \\
& L_{i j} \text { —Distance between pivot }{ }^{i} \text { and }{ }^{j}(i, j=1,2,3,4,5,6 \text { 且 } i \neq j), \mathrm{m} \text {; } \\
& F_{i} \text { _- Pivot point }{ }^{i} \text { constraint force }(i=1,2,3,4,5,6), \mathrm{N} \text {; } \\
& q \text { - Equivalent rail gravity uniformly distributed load, } \mathrm{KN} / \mathrm{m} \text {; }
\end{aligned}
$$

Calculate $F_{2}, F_{3}, F_{4}, F_{5}$ by formula (1), (2), (3), (4).

Then calculate by the balance of torque available:

$$
\begin{aligned}
& L_{12} F_{2}+L_{13} F_{3}+L_{14} F_{4}+ \\
& L_{15} F_{5}+L F_{6}-0.5 L G=0
\end{aligned}
$$

The supporting force is equal to the gravity:

$$
F_{1}+F_{2}+F_{3}+F_{4}+F_{5}+F_{6}-G=0
$$

Calculate $F_{1} 、 F_{6}$ by formula $(5),(6)$.

B. The calculation principle of weight vehicle bogies bear

As shown in Figure 3: analyse the force on the car floor, and T1, T2, T3 represent pressure on the car floor, and they are equal to $F_{1} 、 F_{2} 、 F_{3}$, and $N 1$, N2 represent the vehicle bogie supporting force on the car floor. According to the principle of moment balance, calculates the vehicle bogie bearing weight, and to determine whether there is unbalanced weight.

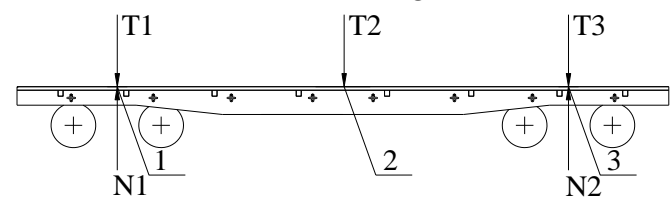

Figure 3. Pressure on flat car floor

$$
T_{2} \times L_{12}+T_{3} \times\left(L_{12}+L_{23}\right)=N_{2} \times\left(L_{12}+L_{23}\right)
$$

$$
\begin{aligned}
& T_{2} \times L_{23}+T_{1} \times\left(L_{12}+L_{23}\right)=N_{1} \times\left(L_{12}+L_{23}\right) \\
& \text { Calculate by formula }(7),(8) \\
& N_{1}= {\left[T_{2} \times L_{12}+T_{1} \times\left(L_{12}+L_{23}\right)\right] \div\left(L_{12}+L_{23}\right) } \\
& N_{2}= {\left[T_{2} \times L_{12}+T_{3} \times\left(L_{12}+L_{23}\right)\right] \div\left(L_{12}+L_{23}\right) }
\end{aligned}
$$

\section{ESTABLISH THE FINITE ELEMENT MODEL OF RAIL}

\section{A. Establish 3D entity model}

Establish 3D entity model in Solidworks ${ }^{[5]}$, As shown in Figure 4.

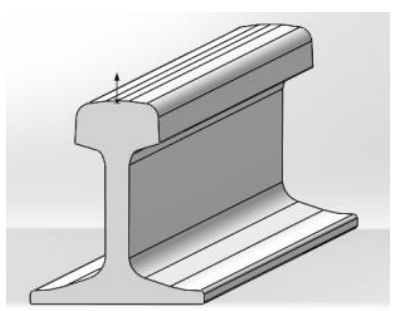

Figure 4. Entity model of rail

\section{B. Definition of materials and mesh}

Mesh in Hypermesh, and use steel as material. The attribute data: density is $7.8 \mathrm{~g} / \mathrm{cm}^{3}$, elastic modulus 202000MPa, Poisson's ratio of 0.3 . 
Considering the precision and speed of calculation, mesh on the rail section ${ }^{[6]}$, and the size of the grid use $10 \mathrm{~mm}$, and mesh on the beam element, the size of the grid use $150 \mathrm{~mm}$, as shown in figure 5 .

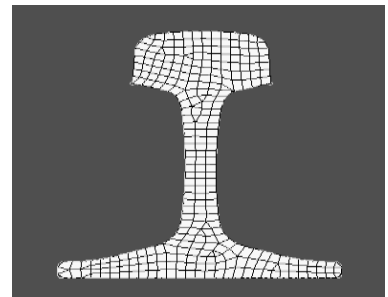

Figure 5. Mesh map of rail

\section{The constraints and the load sets}

When calculating in Ansys, there is need to set constraints. In the rail loading scheme, fulcrum 2,4 are cargo bogies, which need to be make full constraint. Fulcrum 1, 3, 5, 6 are the slipway, which need to be make longitudinal displacement constraint, so as to ensure that the deflection of the fulcrum is zero ${ }^{[7]}$.

When adding load, add gravity which is vertical downward and equal 1 gravity acceleration ${ }^{[8]}$.

\section{Various working condition setting}

As shown in Figure 1, vehicle with fulcrum 1, 2, 3 represent the front vehicle, and vehicle with fulcrum 4,5 ,
6 represent the back vehicle, and the weight difference between two vehicle steerings on the same vehicle represent deviation value. Bogies on fulcrum 1,3,4,6 are respectively bogie 1 , bogie 2 , bogie 3 , bogie 4 , and all working conditions are as follows:

Working condition 1: The height of two vehicle floor is equal and rail doesn't move.

Working condition 2: The difference in height between two vehicle floor is $20 \mathrm{~mm}$ and rail doesn't move.

Working condition 3: The height of two vehicle floor is equal and rail move $150 \mathrm{~mm}$.

Working condition 4: The front vehicle's floor is $20 \mathrm{~mm}$ lower than the back vehicle's floor and rail move $150 \mathrm{~mm}$ towards fulcrum 1 .

Working condition 5: The front vehicle's floor is $20 \mathrm{~mm}$ lower than the back vehicle's floor and rail move $150 \mathrm{~mm}$ towards fulcrum $6^{[9]}$.

\section{FINITE ELEMENT ANALYSIS RESULTS}

Make finite element calculation in Ansys, and the calculation results are shown in table 1 .

TABLE I. PRESSURE ON BOGIE IN DIFFERENT CONDITION/T

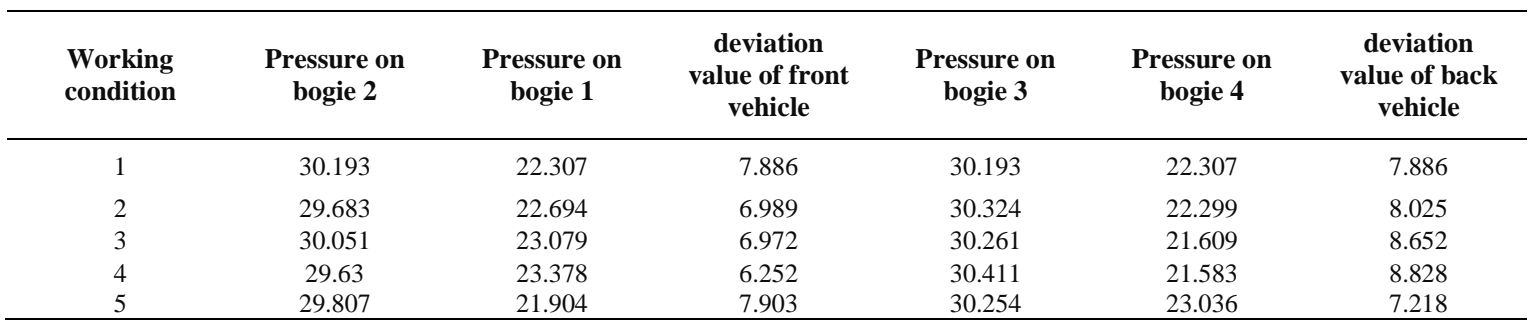

From table 1, in various working conditions, there is unbalanced weight happening, and the weight bogie 3 bears is 30.411 t in working condition 4 , which is the maximum value in all working conditions, so working condition 4 is the worst working condition. The weight bogie bears is $30.193 \mathrm{t}$ in working condition 1 , which is the minimum value in all working conditions, so working condition 1 is the best working condition. The calculation result is consistent with the actual situation ${ }^{[10]}$.

\section{CONCLUSIONS}

This paper establishes the rail finite element mode and conducts simulation calculation, and the simulation results show that our $25 \mathrm{~m}$ rail transport scheme has unbalanced weight problem, which is consistent with the actual situation. For the further study of the problem to solve the unbalanced weight problem, it can change the height and location of pivot to improve the loading scheme, and finally obtains the feasible scheme to solve the unbalanced weight problems.

\section{ACKNOWLEDGMENT}

This work was financially supported by the Fundamental Research Funds for the Central Universities (2014JBM061)

\section{REFERENCES}

[1] China's Ministry of Railway. Railway Freight Loading Reinforcement Shape Scheme[M]. Beijing: China Railway Publishing House, 2010:150-155.

[2] HAN Mei. Railway Freight Technique[M]. Beijing: Beijing Jiaotong University Publishing House,2013:15-17.

[3] ZHAO Yong, ZHANG Zhong-ping. Discussion on the Deviation Problems of Using 25m Rail Cross-installed in Six-point Freight Bogie[J]. Railway Freight,2011,01:35 -37.

[4] ZHU Ying, JIANG Yong-li. Engineering Mechanics[M]. Beijing: Beijing Jiaotong University Publishing House,2010:32-34. 
[5] ZHAO Fu, QING Zhi-feng, WANG Yu-fei. Chinese Version of SolidWorks 2013 from Entry to the Master[M].Beijing: Weapon Industry Publishing House,2013:98-101.

[6] ZHOU Chuan-yue. HyperMesh from Entry to the Master[M].Beijing: Science Publishing House,2005:74-76.

[7] CHEN Chao, HAN Mei, WANG Yan-ling. Study on Allowable Lateral Deviation of the Center of Gravity of Goods Based on Safety Criteria Regarding Derailment Coefficient[J]. Journal of the China Railway Society,2008, 30(2):12-16.
[8] DING Yuan, WU Ji-hua. Ansys CFX 14.0 from Entry to the Master[M]. Beijing: Tsinghua University Publishing House, 2013:154-157.

[9] Yang Guang-quan,Ma Yu-kun. Study on vehicle bearing ordinary flat car for transport of $100 \mathrm{~m}$ long rail based on simulation[J]. Railway Freight, 2012,03:37-42+4.

[10] Peng Yong-zhao,Lang Mao-xiang,Liu Jiang-tao. Summary on the Research of Loading and Reinforcing of Chinese Railway Goods with Exceptional Dimensions[J].Logistics technology, 2009,11:31$34+38$. 